\title{
Preparation and Investigation of Coal Slurry Fuel Blended with Industrial Wastewater for use in Thermal Power Generation
}

\author{
Mueed Akhtar ${ }^{1}$, Ehsan Ali $^{1}$
}

\begin{abstract}
:
The scientific novelty of the research is that coal slurry fuels have been prepared by blending pulverized coal with industrial effluents and characteristics were compared with the slurry comprising fresh water. This innovative technique results in saving fresh water. Also, this methodology puts local coal reserves of Pakistan to use in an innovative way which is both efficient and friendlier. This novel idea puts local coal in use for power production. The coal in Pakistan in not in use because of the difficulties in mining and also due to the lack of concern of the government regarding using countries own resources for power production. Instead the policies regarding importing expensive fuels from Gulf States are a common practice. The novelty of this idea serves the idea of both greener and sustainability of energy.
\end{abstract}

Keywords: Coal, Coal slurry Fuel, waste water

\section{Introduction}

Pakistan is majorly an agriculture-based economy but in the past decade there has been a major development in the industrial sector. This industrial development results in more energy requirements and more consumption. In Pakistan total installed capacity of power generation is 22,000 MW. Average production of power is almost $17,000 \mathrm{MW}$ and the shortfall of energy lies between 5,000 MW to $6,000 \mathrm{MW}$. Total $80.7 \%$ of the supply in the energy mix of Pakistan is dominated by oil and gas combined. In fiscal year 2013-2014 energy production from oil was $32 \%$ of the total energy mix. From gas $34 \%$ of the total energy mix is produced. From coal 3,590,386 TOE were generated and it was $0.1 \%$ of the total energy mix. Besides fossil fuels, the other major source of energy is hydel from which total of $30 \%$ of the total energy mix.
Rest is obtained by nuclear and other resources like renewables and LPG etc.[1].

In Pakistan, vast quantities of coal are present. Each province has got substantial amount of coal reserves. Reserves and their calorific values are shown in the table below.

\footnotetext{
${ }^{1}$ School of Chemical Engineering, The University of Faisalabad, TUF, Faisalabad, Pakistan

Corresponding Email: mueed.akhtar@tuf.edu.pk
} 
TABLE I. Coal Reserves

\begin{tabular}{|c|c|c|}
\hline Province & $\begin{array}{l}\text { Reserves } \\
\text { (million } \\
\text { tons of } \\
\text { coal) }\end{array}$ & $\begin{array}{l}\text { Calorific } \\
\text { value } \\
\text { (BTU/Lb) }\end{array}$ \\
\hline Sindh & $1,84,623$ & $\begin{array}{l}5,219- \\
13,555\end{array}$ \\
\hline Baluchistan & 217 & $\begin{array}{l}9,637- \\
15,499\end{array}$ \\
\hline Punjab & 235 & $\begin{array}{l}9,472- \\
15,801\end{array}$ \\
\hline KPK & 91 & $\begin{array}{l}9,386- \\
14,217\end{array}$ \\
\hline AJK & 9 & $\begin{array}{l}7,336- \\
12,338\end{array}$ \\
\hline Total & 185,175 & \\
\hline
\end{tabular}

From the above data it is quite clear that Pakistan has more than enough coal resources. With these resources Pakistan can generate 100,000 MW of energy for more or less 30 years. In Pakistan most of the coal found has either high Sulphur values or high moisture content. If the coal has perfect quantities of all the components, the coal is in very little quantities. It is clear that the largest coal reserve in Sindh is Thar coal which 175.5 billion out of 184 billion of total reserves of Sindh. But it contains 29.60-55.50\% moisture. Total coal reserves in Baluchistan are 217 million tons out of which 32 million tones are considered to be mineable. The classification of coal is sub-bituminous to bituminous. Heating values are in the range of 9,637$15,499 \mathrm{Btu} / \mathrm{lb}$ with low ash contents but high sulfur contents. Now talking about Punjab, the total coal reserve is reported to be 22 million tons. It has relatively low moisture, ash content and sulfur content than salt range coal mine, but still not up to mark the optimum quality coal. Quality of coal is also qualified as sub-bituminous coal. In KPK, there are combined reserves estimated to be 91 million tons. Coal of both mines is reported to be subbituminous with heating values in the range of 9,386-14,217 Btu/lb. Coal from both mines have low Sulphur and ash contents also with low moisture contents[2].

\subsection{Environmental Issues}

Pakistan is a developing country. In Pakistan, there are multiple industries, growing day by day. Also the population of Pakistan is increasing day by day. Pakistan is now the home of more than 200 million people. Increased population means more energy requirement, more consumer products, more industrial growth, also more municipal waste and industrial waste. Pakistan is basically an agriculture-based economy but now this economy is shifting towards industry. There are textile mills, sugar mills, cement plants, fertilizer plants, consumer products industry, and food \& beverage industry. All these industries use water for processing. If water is used for processing, obviously there is some water wastage.

Pakistan is a country where most of its energy is produced from fossil fuels like oil and gas. A very less amount of energy is produced from renewables. In the recent years there is a remarkable shift in the government's policy, to make the process of making energy efficient, green, cleaner and sustainable.

To have a long term sustainable better economy, Pakistan must address the environmental challenges which comes along with a better and stable economy. These problems include industrial waste water, municipal waste water, chemical spills in clean water, soil erosion, deforestation, salinity, water logging, fresh water pollution, just to name a few.

\subsubsection{Water pollution}

In Pakistan, water gets polluted by a number of means. Mainly these are classified into following classes.

- Water pollution due to raw sewage.

- Water pollution due to industrial waste water.

- Water pollution due to agriculture runoffs.

All these pollutions have driven fresh water supply to a limited amount. Majority of the population does not have proper supply of fresh drinking water. Urbanization and implementation of modern technologies is also causing the pollution of water. According to the research conducted by Pakistan Medical Research Council, majority of the diseases in common population is caused by drinking of substandard or polluted water. This water 
pollution is causing many diseases like typhoid, cholera and other gastric diseases. This polluted water when seeps through the soil, mixed with pockets of fresh underground water also makes it polluted[3].

\subsection{Coal Water Slurry Fuel}

CWS is a fuel which consists of finely pulverized (less than 20 micrometers in diameter) coal particles suspended in water in the presence of emulsifying agents/oil/stabilizers. CWS usually consists of $55-70 \%$ of pulverized dispersed coal particles and $30-45 \%$ of water. Coal-water slurry fuel classified based on following properties: ignition temperature $800-850 \quad{ }^{\circ} \mathrm{C}$, combustion temperature $950-1150^{\circ} \mathrm{C}$, and calorific value $5800-6500 \mathrm{kcal} / \mathrm{kg}$. This fuel can be used to fire boilers for steam production. Another application for this type of slurry is gasification. At present there are multiple gasification processes developed to utilize this technology like GE energy (Texaco), opposed multi-burner process, etc.[4].

The most desirable features of CWSF are high solid loading, good stability, good rheological behavior, low viscosity, low ash content and relatively high heating values. Usually CWSF is prepared by maintaining a solid to water loading of $70 \%$ and $30 \%$ respectively. These ratios may vary from 70:30 - 60:40. If water is added above $40 \%$, then heating value of the fuel will be decreased. A small percentage (up to $1 \%$ ) of additives is also added for better dispersion, uniformity and stability of solid loading[5].

\section{Materials and methods}

Coal was obtained from Pioneer Cement Pvt. Ltd Plant located near Khushab district, Pakistan. They imported the coal from Waterberg coal field located in South Africa. The coal obtained was already pulverized and the average particle size was $90 \mu \mathrm{m}$. This coal was mixed with three different industrial waste waters. Spent wash was obtained from Noon Sugar Mills Distillery Pvt. Ltd located in Bhalwal near Sargodha district, Pakistan. Similarly, waste water was obtained from Fauji Foods located in Bhalwal near Sargodha district, Pakistan and Sapphire textile mills limited located in Lahore, Pakistan. An ionic surfactant named as sodium naphthalene sulfonate formaldehyde condensate was selected as dispersant which was imported from SHANDONG WANSHAN CHEMICAL CO. Ltd., China and Sodium lingo-sulfite was selected as the stabilizer which was imported from Jinan Yuan sheng Chemical Technology Co., Ltd, China. All the raw materials were collected and brought to the Bio Fuels lab at USPCAS-E NUST, Islamabad Pakistan. For both types of slurries solid loading was kept $65 \%$ and liquid ratio was kept $35 \%$ by weight. $1 \%$ additives were added, both in equal quantities. $400 \mathrm{~g}$ samples of both slurries were prepared in a mixer driven by $800 \mathrm{w}$ variable speed motor. $260 \mathrm{~g}$ of coal, $139 \mathrm{~g}$ of water, $0.5 \mathrm{~g}$ of NaNSF and $0.5 \mathrm{~g}$ of sodium lignosulfite were added into the container and then mixed at 1357 RPM for 30 minutes. After 30 minutes the coal water slurry fuel (CWSF) was collected into sample bottles. The same procedure was repeated with waste waters to make coal waste water slurry fuels (CWWSF) under ambient conditions.

\section{Results and Discussions}

After preparing samples of all the slurries, these samples were sent to Pioneer Cement for testing. Three types of tests were performed on both the samples. The tests carried out were focused on finding out the qualities of the fuel in order to determine whether or not it could be used effectively.

A number of tests were performed to determine the quality of coal. These tests include \% total moisture (ISO 11722), \% Ash content (ISO 1171), \% Sulphur (ISO 351), \% inherent moisture (ISO 331), \% volatile matter (ISO 351) and Calorific value (ISO 1928). All the samples were prepared at Pioneer Cement. As all of them were prepared from finely pulverized coal, now size reduction for the preparation of samples were needed. All the samples were dried by placing them in an air circulated furnace a 40 degree Celsius. After performing the analysis, the following analysis were obtained. 
TABLE II. Analysis of Coal, CWSF and CWWSF samples

\begin{tabular}{|l|l|l|l|l|l|l|}
\hline $\begin{array}{l}\text { Sr. } \\
\text { No. }\end{array}$ & Analysis & Coal & $\begin{array}{l}\text { Coal } \\
\text { Water } \\
\text { Slurry } \\
\text { Fuel }\end{array}$ & $\begin{array}{l}\text { Coal } \\
\text { Waste } \\
\text { Water } \\
\text { Slurry } \\
\text { Fuel } \\
\text { (Textile) }\end{array}$ & $\begin{array}{l}\text { Coal Waste } \\
\text { Water Slurry } \\
\text { Fuel(Alcohol } \\
\text { Distillery) }\end{array}$ & $\begin{array}{l}\text { Coal } \\
\text { Waste } \\
\text { Water } \\
\text { Slurry } \\
\text { Fuel } \\
\text { (Dairy) }\end{array}$ \\
\hline 1 & $\begin{array}{l}\% \text { Inherent } \\
\text { Moisture }\end{array}$ & - & 2.46 & 1.77 & 1.42 & 1.48 \\
\hline 2 & $\%$ Total Moisture & 3.12 & 38.94 & 39.45 & 35.54 & 38.22 \\
\hline 3 & $\%$ ASH Content & 16.22 & 16.72 & 16.56 & 17.86 & 16.80 \\
\hline 4 & $\begin{array}{l}\% \text { Volatile Matter } \\
\text { \% Sulphur }\end{array}$ & 30.69 & 30.64 & 27.01 & 28.41 & 26.99 \\
\hline 5 & 0.69 & 0.81 & 0.83 & 0.96 & 0.85 \\
\hline 6 & $\begin{array}{l}\text { Gross Calorific } \\
\text { Value } \\
\text { (callgm)ADB }\end{array}$ & 6260 & 6245 & 6228 & 6014 & 6209 \\
\hline
\end{tabular}

In the above table, there are given the properties of five samples. One being the coal and other four are coal slurry fuels. Coal is marked as a basic standard and all other values are for comparison. All the samples of coal slurry fuel have inherent moisture. This is due to the presence of water in the form of fresh water or in the form of waste water. Also due to this same reason the total moisture in the coal slurry samples is higher.

Ash contents of all the samples are almost the same as that of coal sample except the CWWSF (Alcohol Distillery). This is because of the properties of alcohol distillery spent wash. Spent wash already contains solid material. Volatile material in CWSF is in accordance with the coal sample. But for CWWSF sample the levels are different. This is again due to the different properties of different waste waters. Sulphur content in coal sample is $0.69 \%$. This value is perfect for use in thermal power generation. It should be less than $1 \%$. In CWWSF sample this value is different but all the values are within the range. Coal sample has the maximum GCV, all CWWSF samples have lowered GCVs but this difference is negligible.

\section{Recommendations}

On the basis of all the above discussions it is obvious that all the samples CWWSF are feasible for use in thermal power production.
This solves many problems. The Coal Slurry fuels are easy to handle. They have better combustion efficiencies. Ash formation after combustion is less. SOx emissions after combustion is also low. This is because of its composition. It contains water which forms acids with sulphur. Due to these acids formation there are low SOx emissions. Also NOx emissions are reduced due to the presence of water in the slurry. The slurry is combusted at lower temperatures. NOx are produced due to the combustion at high temperatures. This is the only reason of low NOx productions. [6] But there is also a down side. We need to make modifications in the internal design of the existing and new boilerlsteam generation systems. Corrosion is accelerated due to the production of acids during combustion. This is a serious problem. It shortens the life of equipment increases, wear and tear. If not inspected and evaluated, it may cause serious damage to internal parts of the boiler/steam generator. It also makes maintenance of equipment more difficult. To prevent this, we need to preinstall an anticorrosive coating on the internal parts of the boiler/steam generator. Plus, if we replace this fuel in existing systems, we need to make major modifications in the design. For example, if the existing system is on furnace oil, we need to install a new CSF based burner. Also some modification is need to extract ash from the system. The same modifications are 
needed if Natural gas based thermal systems are installed. Mostly if natural gas based systems are installed, they use gas turbines instead of boilers/ steam generators. Some modifications are also required in the process.
The wet milling equipment is required to prepare the slurry. Also some slurry pumps are required for pumping and transport. A suggested flow sheet diagram is shown below.

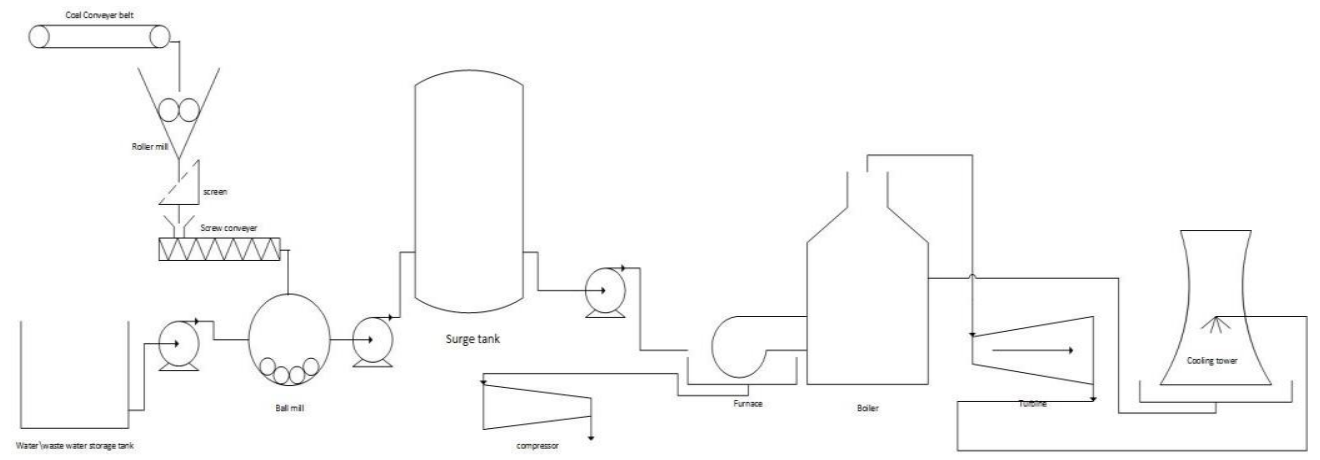

Fig 1: Flow sheet diagram

According to some literature energy production from CWSF is cheaper than Furnace oil and Gas.

TABLE III: Cost comparison

\begin{tabular}{|c|c|c|}
\hline Sr. No & Fuel & PricelMJ (PKR) \\
\hline 1 & Furnace oil & 2.6 \\
\hline 2 & Natural Gas & 0.63 \\
\hline 3 & CWSF & 0.42 \\
\hline
\end{tabular}

Although there is a very small difference between Natural gas and CWSF, gas reserves in Pakistan are depleting. Government is trying to import LNG as a solution but it is expensive. So this difference will not be very little if compared with LNG[7].

\section{Conclusion}

Energy production and waste water treatment are two major issues in the world and especially for Pakistan. Energy production from coal is usually avoided due to its environmental hazards. But according to the depleting conditions of other two resources (oil and gas). We need to divert the production of energy from oil and gas to coal to balance it out and to make it somewhat sustainable. Coal gasification, coal to liquid technologies are some of the greener technologies but they are very expensive. Instead Coal Slurry fuel technology is much cheaper and feasible and if we use waste water instead of fresh water then the problem can be addressed for waste water treatment or waste water disposal. From the experiments conducted following points can be concluded.
- All the properties of CWWSF are in accordance with coal sample, which means the CWWSF are viable for use in thermal power production.

- Some capital investment is required for retrofitting the existing systems and acquiring new systems.

- Ash formed is best fit to be used as filler in the production of concrete.

- Per MJ of energy cost of production from CWSF is less than when produced from furnace oil and natural gas.

- Less Sox and NOx emissions are recorded by using this fuel.

\section{REFERENCES}

[1] C. H. D. I. of Pakistan, "Pakistan Energy Yearbook," 2014.

[2] Private Power and Infrastructure Board, "Power, Coal Potential, Generation," 2004. 
Mueed Akhtar (et-al), Preparation and investigation of coal slurry fuel blended with industrial wastewater for use in thermal power generation

[3] S. R. (University of Karachi), "Environmental Challenges in Pakistan," sharnoffs global views, 2014.

[4] J. Zhu, G. Zhang, G. Liu, Q. Qu, and Y. $\mathrm{Li}$, "Investigation on the rheological and stability characteristics of coal-water slurry with long side-chain polycarboxylate dispersant," Fuel Process. Technol., vol. 118, pp. 187-191, 2014.

[5] Q. He, D. Xie, R. Xu, T. Wang, and B. $\mathrm{Hu}$, "The utilization of sewage sludge by blending with coal water slurry," Fuel, vol. 159, pp. 40-44, 2015.
[6] X. Zhao, W. Zhu, J. Huang, M. Li, and M. Gong, "Emission characteristics of PCDD/Fs, PAHs and PCBs during the combustion of sludge-coal water slurry," J. Energy Inst., vol. 88, no. 2, pp. 105$111,2015$.

[7] M. Irfan, M. A. Irfan, A. Khan, I. Ullah, N. Wazir, S. Arabia, S. Arabia, and I. Estate, "The Case of Coal Water Slurry Fuel for Industrial Use in Pakistan," vol. 9, no. 6, pp. 460-465, 2015. 